\title{
Health-Seeking Patterns among Fatally Ill Capeverdian Women
}

\author{
Hans Wessel, Pitt Reitmaier ${ }^{2}$, Alice Dupret ${ }^{3}$, Ernesto Rocha ${ }^{4}$, Sven Cnattingius ${ }^{5}$ and Staffan Bergström ${ }^{1}$
}

\begin{abstract}
The circumstances of 94 deaths among females aged 15-49 years in Cape Verde were investigated to assess their access to effective care. Persons associated with the deceased women were interviewed (verbal autopsy) to explore contributing causes of death, perceived illnesses and treatment efforts. The certainty of diagnosis and avoidability of the fatal outcome were assessed by a panel of experts. A model of health care accessibility is elaborated to identify restricting (delay) factors. Deliberate avoidance of modern medical care and reliance on traditional medicine were major delay factors, while unawareness of the severity of symptoms and affordability limits were minor delay factors in this population. A detailed sorting of cases by health care level is used to identify the effectiveness of diagnosing, referral and care provided. Since a high proportion of avoidable deaths occurred in hospital, the quality of care may have been sub-optimal. (AfrJ Reprod Health2004; 8[3]:176-187)
\end{abstract}

\section{RÉSUMÉ}

Modèles de la recherche du bien-être chez les femmes capverdiennes malades. Nous avons étudié les circonstances de la mort des 94 femmes âgées de 15-49 ans au Cap-Vert pour évaluer leur accès au soin effectif. Les gens liés aux femmes décédées ont été interviewés (autopsie verbale) afin d'explorer les causes qui ont contribué à la mort, la maladie aperçue et les efforts de traitement. La certitude du diagnostic et la possibilité d'éviter la conséquence fatale ont été évaluées par un jury d'experts. Un modèle de l'accès au soin de la santé a été élaboré pour identifier les facteurs de retard. L'acte d'éviter consciemment le soin médical moderne ainsi que la confiance en médecine traditionnelle faisaient partie des facteurs de retard majeurs alors que la conscience de la sévérité des symptômes et les limites tolérables constituaient les facteurs moins importants de retard dans cette population. On se sert de la méthode du classement détaillée des cas en se basant sur le niveau du soin médical pour identifier l'efficacité du diagnostic, l'orientation vers un hôpital spécialisé et le soin assuré. Puisque la bonne proportion des décès évitables ont lieu à l'hôpital, la qualité du soin aurait été sous-optimal. (Rev Afr Santé Reprod 2004; 8[3]:176187)

KEY WORDS: Female mortality, cause of death, verbal autopsy, access to care, Cape Verde

Division of International Health (IHCAR), Karolinska Institute, Stockholm, Sweden. ${ }^{2}$ Department of Tropical Hygiene and Public Health, INF 324, University of Heidelberg, Germany. ${ }^{3}$ WHO, Praia, Cape Verde. ${ }^{4}$ Department of Obstetrics and Gynecology, Baptista da Sousa Hospital, Sao Vicente, Cape Verde. ${ }^{5}$ Department of Medical Epidemiology and Biostatistics, Karolinska Institute, Stockholm, Sweden.

Correspondence: Hans Wessel, Department of Women's Health, Karolinska Hospital, SE-171 76 Stockholm, Sweden. Tel: +46851775870; Fax: +468-51776194;E-mail:hans.wessel@ks.se 


\section{Introduction}

Causes of illness and death can be difficult to verify in poor settings. The obvious reasons for this are lack of personnel, diagnostic tools and proper transportation as well as a low proportion of patients under medical observation, short time spans between death and burial, and, locally, socio-cultural barriers to post-mortem examinations. Where information is scant, investigations of causes of severe morbidity and mortality have to rely on unorthodox methods of data collection. $^{1-3}$ The verbal autopsy method utilises information obtained through retrospective interviews of relatives or associates of a deceased person to assess the cause of death. It has been extensively validated as a means of assessing causes of childhood and maternal deaths.

The 420,000 inhabitants of Cape Verde gain their livelihood from tourism, foreign aid, small scale industry, fishing and agriculture. In 1996, the gross national product per capita was US $\$ 700$, with an annual increase of $3 \%$. The population growth was $2.8 \%$ per year, crude birth rate (per 1000 population) was 36.2, crude death rate was 8.6 , total fertility rate (per woman) was 4.3 , and adult literacy rate for both sexes was $67 \% .^{12-14}$ Vital statistics have repeatedly proven reliable regarding number of deaths although the official classification of causes is incomplete. $^{15-17}$

We have previously reported the distribution of causes of death among Capeverdian women aged 15-49 years, the reliability of diagnosis and the theoretical avoidability of fatal outcome. ${ }^{14}$ The most frequent causes of death were circulatory disorders, external causes, maternal causes, infectious diseases and neoplasms. A plausible diagnosis could be determined in $77 \%$. Seventy one per cent were estimated to be avoidable.
This study aims at investigating healthseeking patterns among fatally ill Capeverdian women, identifying the perceived causes of death and the perceived access to effective care among people close to women who died at fertile age regardless of cause. We therefore interviewed family members of the deceased, scrutinised hospital files and interviewed modern and traditional health service providers. Special interest was devoted to the women who died from theoretically treatable conditions. The cases were sorted by level of care provided and by perceived obstructions to effective care. Based on these findings, a health-seeking model was constructed to show the relative importance of various restrictions to effective care.

\section{Subjects and Methods}

The inhabitants of the three islands, Santiago, Sao Vicente and Santo Antao comprise $80 \%$ of the Capeverdian population. During one year, starting in October 1992, 97 women aged 15-49 years died in this area. Circumstances surrounding their deaths were investigated. The selection criteria, case identification and cause of death ascertainment have been described elsewhere. ${ }^{14}$ When a death occurred, the family of the deceased person was contacted and acceptance for later interviews was sought among family members and other knowledgeable persons. Left-over drugs and other items of interest were identified for later analysis of the cause of death.

Female social workers performed the semi-structured narrative interviews with a recall period of 3-14 months. If needed, the interviews were repeated once or twice until 
the chain of events leading to death and the health-seeking behaviour became fully understood. Interview setting was based on the interviewee's choice, e.g., whether other family members or neighbours could attend and the language used (Creole or Portuguese). A majority of the interviews were conducted in the home of the interviewee and the duration ranged from five minutes to two hours.

In the 80 cases treated in hospital, information was also obtained from the patients' files. In 36 of those cases, professional health staffs were interviewed. Post-mortem examinations were performed only if a crime was suspected.

Two regional groups of senior physicians and the authors analysed all data, such as hospital files, narratives and left-over drugs, to assign the cause of death according to the International Statistical Classification of Diseases and Related Health Problems, 10th Revision (ICD+10). Comparing with the stated cause on the death certificate in each case, the reliability of the latter diagnosis was assessed.

To judge whether an injury or illness would unavoidably lead to the death of a person, the panel applied the following reasoning: as long as an efficient medical treatment existed somewhere in the country, the injuries or diseases were regarded treatable. Heart surgery and cancer treatment were not available, hence, rheumatic heart valve disease and breast cancer were regarded as unavoidable causes of death. Preventable causes included those controllable by immunisation, e.g., tuberculosis or other preventive measures like alcoholism.
The study was ethically approved by the WHO/Safe Motherhood Initiative, Geneva, and by the Ministry of Health, Praia, Cape Verde.

\section{Results}

Ninety seven of the 59,333 women at risk died during the 12-month study period. One family disapproved of being interviewed, one family had moved from the study area, and one family could not be located, leaving 94 cases to be included in the study. Altogether, 207 interviews were conducted.

The 94 deceased women were evenly distributed throughout the islands. Agespecific mortality increased evenly from 59 per 100,000 among women aged 15-19 years to 480 per 100,000 among women aged 45-49 years. The level of education among the deceased women mirrored that of the female population as a whole: $38 \%$ had no school education, 54\% had studied for 1-4 years, while $8 \%$ had studied for five years or more. ${ }^{12}$ The median number of children was 5 (range 0-13). The proportion of married and cohabiting women was of the same order among those who died (48\%) and the general female population (42\%). Two per cent of the nation's female population is considered physically or mentally handicapped to a degree that impedes an occupation, while among the deceased women $13 \%$ were handicapped. Twelve deaths (13\%) were drug or alcohol-related.

Most women (62 of 94) died in hospital. Twenty one of the 32 patients who died at home had previously visited hospitals to treat their last illness. Six of the women died outdoors (three in car accidents, two drowned and one fell off a cliff). The four patients who 
died on the way to hospital suffered from heart valve disorder, bronchial asthma, spontaneous abortion and a broken neck (murder). Six terminally ill patients were sent home from hospital to die amidst their families.

There were no reliable data on the time interval between the decision to seek modern medical care and the arrival at a care facility, but various kinds of patient's delay could be demonstrated. These included lack of awareness of the severity of their health condition; inability to afford transport costs, service fees and drug prices; consulting with inappropriate care provider; not reaching a care facility because of lack of telephones or transport; and deliberate refusal to seek care.

Out of a total of 94 women, nine died immediately without the option of seeking medical care, and 37 (44\%) of those who sought help were delayed. The most frequent causes of delay were, resenting the option of immediate modern care (16 cases) and inappropriate health care provider (13 cases) (Figure 1).

Thirteen families $(14 \%)$ had a different opinion from that of medical staff on the cause of death of their relative. This was commonly observed among those families that primarily sought help with traditional healers (5 of 13 [48\%]). The two major diverging conceptions involved regarding deaths from diseases or injuries as "God's will" or provoked by magical influences from personal enemies.

Among the 73 cases with a certain or probable cause of death, 40 were classified as preventable, 28 as treatable (16 cases overlapped) and 21 as unavoidable. The most common preventable causes were stroke (6), tuberculosis (5), HIV (5), other infectious diseases (5) and traffic accidents (4). Among the unavoidable causes of death, heart valve disease (7) and genital cancer (7) were the most frequent, followed by breast cancer (4) and hypertension (3). The patient flow charts (Figures 2 and 3) demonstrate that the large majority of patients $(89 \%)$ with treatable disorders were seen by a doctor, and that $75 \%$ reached the highest specialised care.

Among the 28 women with treatable conditions, level of care and causes of death are illustrated in Figure 2. All 28 women had sought medical care. Eleven patients were seen at the nurse-run health posts; three died there or later at home while eight were referred to second or third level of care. Eleven patients visited the peripheral hospitals. Two died there, two died later at home, while seven were referred to third level of care, i.e., the central hospitals. Altogether, 21 women were seen at the central hospitals and the majority (18) died there, while three women died later at home. No patient was referred for treatment abroad.

Sixteen of the 28 deceased women with treatable causes of death reached care facility with some sort of delay (Figure 3 ). The family with the epileptic patient did not understand how serious the condition was. Four women with infectious diseases (tuberculosis, pneumonia or puerperal septicaemia) chose a traditional healer before eventually accessing modern care. One family (diabetes mellitus) could not afford daily insulin injections. Two cases (bronchial asthma and obstructed labour) were hindered by poor infrastructure, while eight patients (pelvoperitonitis, appendicitis, retained placenta, tuberculosis, hypertension with congestive heart failure, alcoholism, endometritis post-abortem, and liver disease) abstained from seeking care in time despite being fully informed and having easy access. 


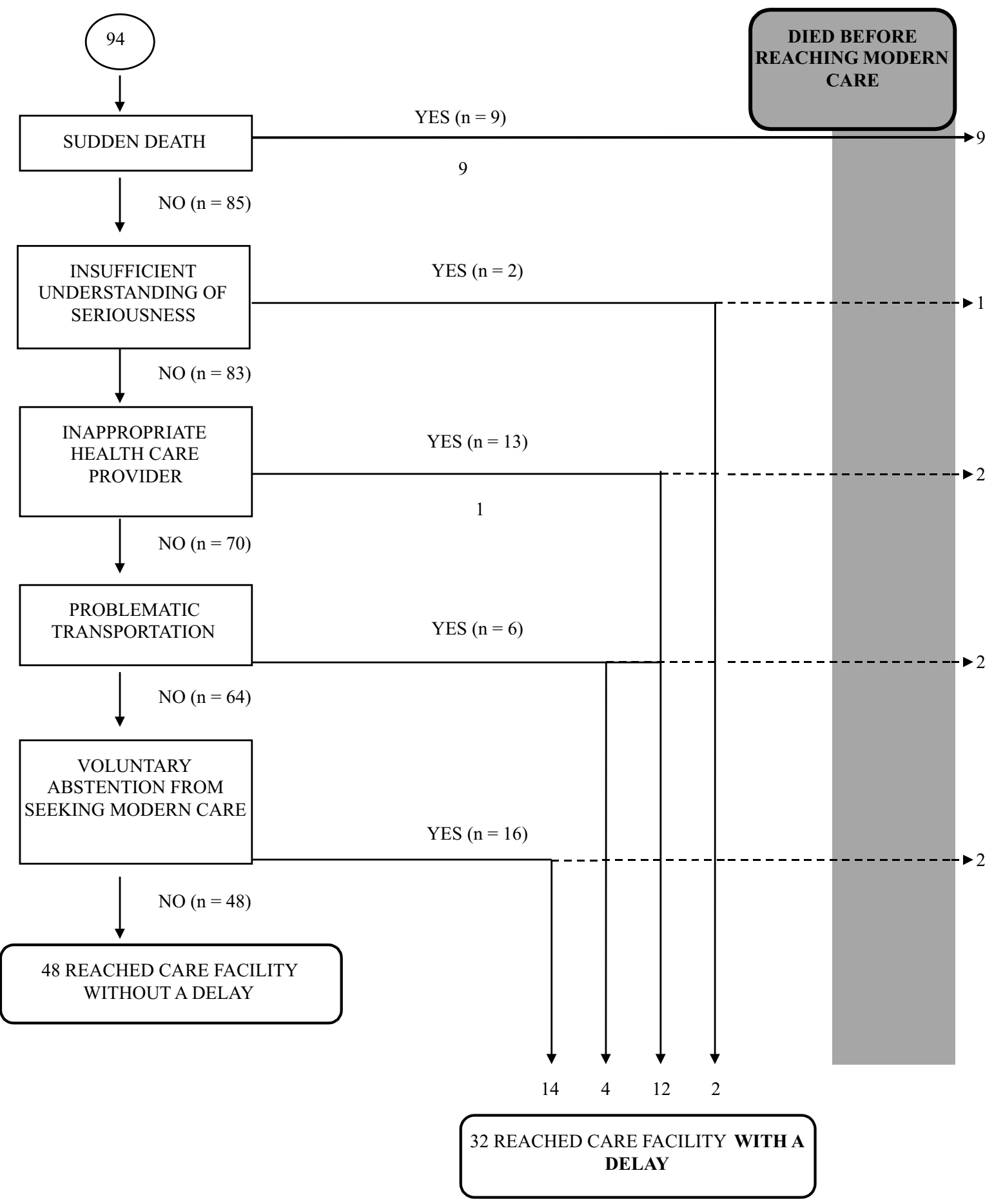

Figure 1 Care Delay Factors among 94 Women who Died 15-49 Years Old in Cape Verde 1992-1993 


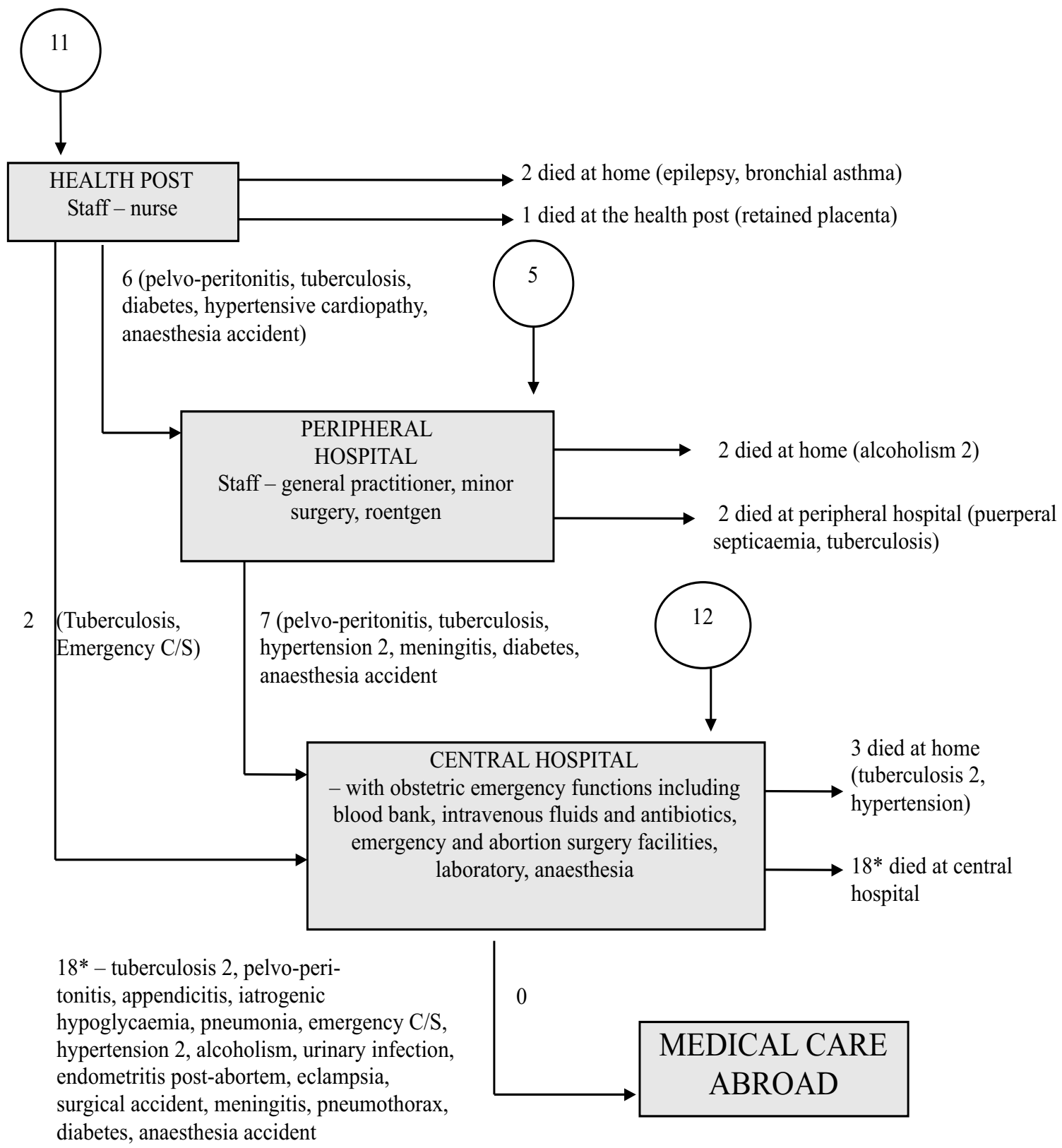

Figure 2 Level of Care among 28 Women Who Died from Treatable Diseases and Injuries, Cape Verde 1992-93 


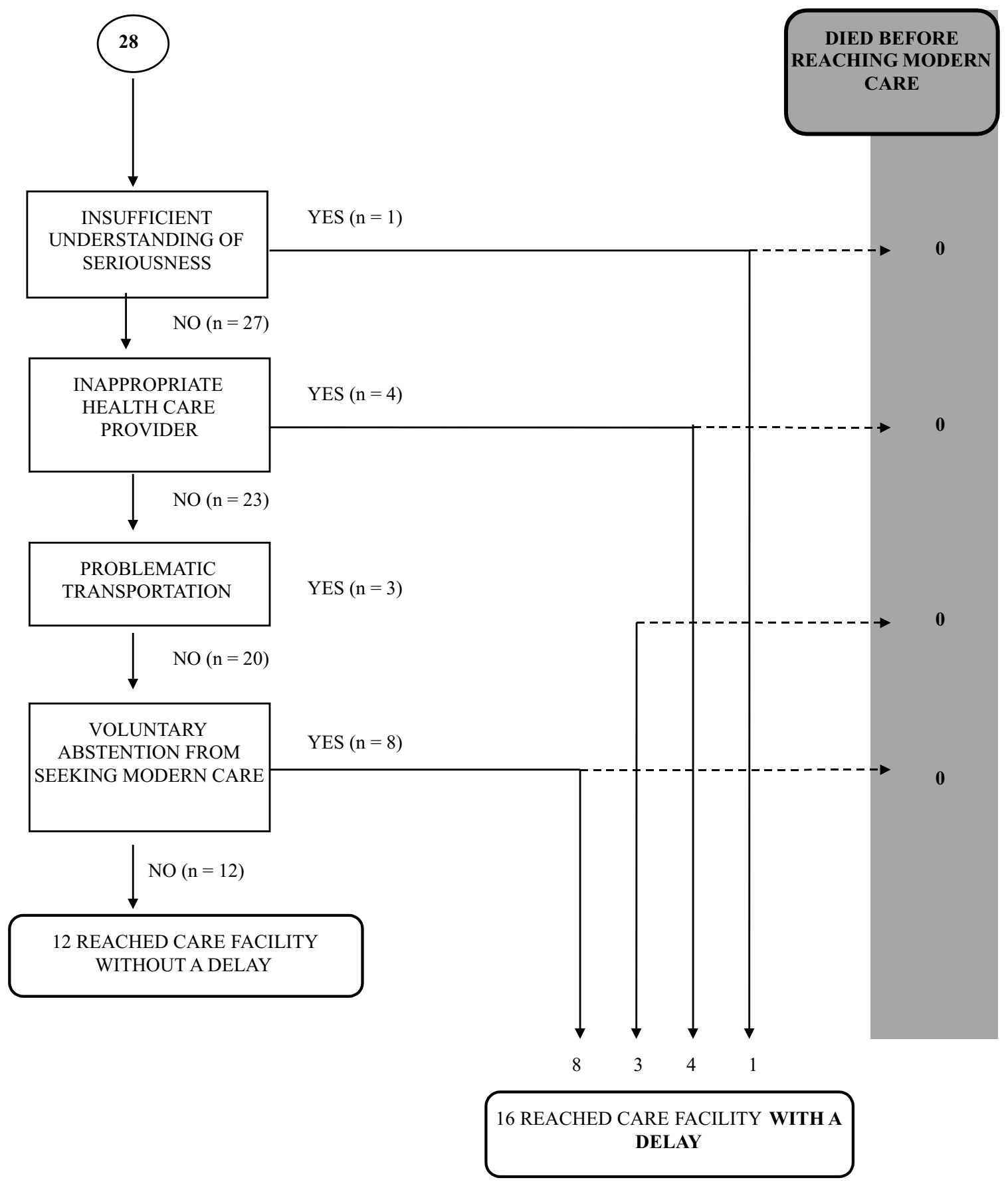

Figure 3 Care Delay Factors among 28 Capeverdian Women Aged 15-49 Years

Who Died from Identified and Treatable Causes in 1992-1993 


\section{Discussion}

The interviews with lay respondents on circumstances of the death of women of reproductive age yielded important supplementary information to hospital records on the underlying cause of death and on the contributing factors. Disbelief in the official health care system; lack of awareness of the seriousness of the disease; inability to afford transport fare, service or drug fees; and infrastructural problems constitute the main factors of "patient's delay". A high proportion of avoidable deaths among these predominantly in-patients suggests that the quality of hospital care may be sub-standard.

Qualitative data on patient's delay can be organised in a logical sequence in a flow chart (Figures 1 and 3) a health-seeking model for delay factors on the road to effective care. Starting with the total number of observed deaths, we first subtract persons are who die suddenly, often unexpectedly, e.g., in a traffic accident, and without the possibility to reach modern health care. Second, cases with insufficient understanding of the seriousness of the disorder/injury (and therefore do not seek care) are withdrawn. Third, among those who seek care, some turn to inappropriate health providers, e.g., a herbal healer, when seriously infected. Fourth, among those who intend to seek modern health care, some are hindered by lack of quick communication and transportation. There may be no telephones, no roads, no cars, or the costs associated with care or transportation may be too high. Fifth, in spite of adequate physical and economic access, some persons choose not to seek modern health care.
A health-seeking model presented by Thaddeus and Maine in $1990^{18}$ distinguishes patient-related from doctor-related restrictions to effective care. Furthermore, community factors such as communications are commented upon. Our model, however, takes into account the complexity of the patient's health-seeking strategy. In populations where awareness of serious health problems is lacking, the strategy to overcome the restrictions must differ from populations who are aware of but do not believe in the effects of the care provided.

There might be sub-groups of nonattendees not listed here, and some cases would present a variety of delay factors that do not fit easily into the model. However, the flow chart brings attention to the dominating delay factors and indicates in detail which problems health care planners need to address. In the present study, the fact that $89 \%$ of the patients who eventually died from "treatable" disorders were seen by a doctor indicates that the quality of care was suboptimal. The fact that many patients came late on purpose tells us that the so-called "patient's delay" might be intimately linked to the quality of care provided. To what degree the ineffectiveness of health care was due to lack of drugs, equipment, staff or knowledge was not studied.

A majority of the patients utilised some kind of traditional medicine (usually herbs) parallel to modern medical care. The picture emerges of chronically ill patients who try every thinkable treatment, give priority to modern care providers for diagnosis and treatment, but resort to traditional treatments when the "modern" treatments fail. The attitudes of medical professionals towards 
their patients and their ability to convey information are probably of vast importance for health care utilisation, and should be investigated further.

Distance to the next health facility only created severe problems for two residents on the Santo Antao Island, while the inhabitants on the other two islands in the study, where tertiary level medical care is available, did not perceive distance or transportation to medical care as problematic. Community-managed loans or transports for emergencies have not been organised in Cape Verde, where the inhabitants rely on the willingness of neighbour car owners and boat owners to solve acute problems. ${ }^{19}$ For patients being referred from one health facility to another there was free ambulance transport.

Unaffordable costs impeded effective treatment in four cases. In Cape Verde, during the study period, the direct cost of treatment was symbolic. In-patient treatment was totally free. The limits were mainly due to indirect costs of transport, stay of an accompanying person or loss of salary. Consistent with other studies from developing regions, ${ }^{20-24}$ our data suggest that the financial cost of receiving care is often not a major determinant of the decision to seek care.

The interviewers of this study were not medically trained, and the questionnaire used was open, with just a couple of starting questions. It has been argued that important clinical signs could pass unnoticed by lay interviewers. $^{6-7}$ On the other hand, when asking about the health-seeking behaviour and opinions about the provided care, the interviewer benefited from not being an actor within the health care system. Confidence between interviewers and respondents was easily established and only one family withdrew from the study. Furthermore, the lay interviewers were not supposed to reach an opinion about diagnosis during the questioning but merely to forward the data to the assessing panel. We believe that our data collection strategy, with open narrative interviews, facilitated comprehensive reports on medical and other causes of death. The correspondence between registered causes of death and causes concluded by the expert panel was $53 \%$ in general and $31 \%$ concerning maternal deaths. The discrepancy between institutional and lay reporters' diagnoses can be explained by a low rate of medical work-ups and post-mortems obscuring diagnoses within the health care system, or a failing understanding of the disease process among lay people. Our data supports the former explanation.

Our data points at several areas where health policy interventions and improvement of health services are important. The capacity of diagnosing disorders at peripheral health centres must be improved, and unclear cases should be referred to specialised care. With the diversity of anaesthesia equipment available during the study period the safety routines of anaesthesia procedures were not sufficient (one healthy puerperal died of halothane intoxication during a sterilisation operation, and one woman died during a caesarean section in lumbar analgesia). Emergency cases need a quicker access to facilities with adequate diagnostic and therapeutic resources. To achieve this, either peripheral units have to be better equipped or transportation of critically ill patients to central specialised facilities needs to be 
quicker. Within the framework of the prevention of maternal mortality network, a system of community loan funds and transport services for obstetric emergencies were tried in rural Nigeria. ${ }^{19}$ However, the Nigerian intervention was expensive (US $\$ 316$ per transported woman) and is therefore of questionable feasibility in the Capeverdian setting. On two of the three islands studied, infrastructure is not a restriction to effective care, but the islands without tertiary level of care would clearly benefit from better communications. Since 1992/93 when the study was performed public telephones have been installed in most villages. This will probably have improved access to effective care.

Some problems, however, appeared less important. Our findings do not support a need for health campaigns to educate the public on signs and symptoms of severe illnesses. There seems to be few misconceptions regarding the severity of the disorders. The cost of medical care is seldom an effective barrier for the sick person's family.

Attitude towards alcohol consumption must be regarded as liberal in Cape Verde, and this may explain that $13 \%$ of the premature deaths were directly related to alcohol abuse either by the deceased woman herself or by the aggressor. The high prevalence of physical or mental handicaps among the cases probably reflects an under-utilisation of health care for these sub-groups. This could be due to a family's decision not to seek care, or difficult access. However, the quality of care of handicapped patients also merits further investigation.

Among the 94 women, five died of cancer of the uterine cervix and another two died of "uterine cancer", which may have been synonymous with cervical cancer. The positive experience of screening for cervical cancer in other countries calls for this preventive measure in Cape Verde. Likewise, with four cases of breast cancer in the study group, which excludes the maximum incidence age group of 60 , the prospects of breast cancer screening through mammography seem important to consider in this setting.

As in most developing countries, traffic accidents were frequent in the study area. Worldwide the number of traffic victims is quickly increasing and nearly three quarters of road deaths occur in developing countries. $^{25-27}$ The traffic problem of Cape Verde must be confronted through integrated interventions comprising drivers' education, car quality control, control and enforcement of sober driving, and road construction and maintenance. Recently the Capeverdian authorities have passed seat belt laws and prohibited the use of mobile phones while driving.

Like the situation in other developing countries, ${ }^{28-29}$ a profound reliance by our study population on traditional health services makes any suggestion to limit its use unrealistic. Hazardous or harmful lay therapies could not be proven in our study. It is noteworthy, however, that hazardous therapies with lethal consequences were evidenced in modern health care. Both modern and traditional health services were criticised by several interviewees; both providers misdiagnosed, both prescribed without explanation, both refused to attend to and failed to communicate correctly with terminally ill patients. 


\section{Acknowledgments}

The Ministry of Health of Cape Verde, the WHO Safe Motherhood Initiative, Dienste in Übersee/Germany and GTZ financed the studies. The social workers, Teresa Mascarenhas, Isabel Magalhaes, Joana Cacilda Gomes and Francisca Pinto undertook the physically and emotionally stressing task of interviewing. Huge amount of data was compiled and causes of death were assigned by the Capeverdian expert representatives from the fields of public health, obstetrics/gynaecology and internal medicine, namely, Maria Jesús Carvalho, Fátima Monteiro, Alice Dupret, Ernesto Rocha, Emily Santos and Dr José Manuel Aguiar. Our special thanks go to the family members who showed us a way to their thinking and feeling in the difficult times of mourning.

\section{REFERENCES}

1. Fortney JA, Susanti I, Gadalla S, Saleh S, Rogers SM and Potts M. Reproductive mortality in two developing countries. Am J Public Health 1986; 76: 134-138.

2. Berhane $\mathrm{Y}$, Andersson $\mathrm{T}$, Wall S, Byass $\mathrm{P}$ and Högberg U. Aims, options and outcomes in measuring maternal mortality in developing societies. Acta Obstet Gynecol Scand2000; 79(11): 968-972.

3. Wurthwein R, Gbangou A, Sauerborn R and Schmidt CM. Measuring the local burden of disease. A study of years of life lost in sub-Saharan Africa. Int $J$ Epidemiol 2001;30(3): 501-508.

4. Kalter HD, Gray HR, Black RE and Gultiano SA. Validation of post-mortem interviews to ascertain selected causes of death in children. Int $J$ Epidemiol 1990; 19: 380-386.
5. Campbell $\mathrm{O}$ and Ronsmans C. Verbal Autopsies for Maternal Deaths. Geneva:

WHO, Division of Family Health, 1994.

6. Anker M. The effect of misclassification error on reported cause-specific mortality fractions from verbal autopsy. Int $J$ Epidemiol1997; 26(5): 1090-1096.

7. Ronsmans C, Vanneste AM, Chakraborty J and Van Ginneken J. A comparison of three verbal autopsy methods to ascertain levels and causes of maternal deaths in Matlab, Bangladesh. Int J Epidemiol 1998; 27(4): 660-666.

8. Chandramohan D, Rodrigues LC, Maude GH and Hayes RJ. The validity of verbal autopsies for assessing the causes of institutional maternal death. Stud Fam Plann 1998;29(4): 414-422.

9. Quigley MA, Chandramohan D and Rodrigues LC. Diagnostic accuracy of physician review, expert algorithms and data-derived algorithms in adult verbal autopsy. Int J Epidemiol 1999; 28(6): 108-187.

10. Kahn K, Tollman SM, Garenne $M$ and Gear JS. Validation and application of verbal autopsies in a rural area of South Africa. Trop Med Int Health 2000; 5(11): 824-831.

11. Sloan NL, Langer A, Hernandez B, Romero $\mathrm{M}$ and Winikoff $\mathrm{B}$. The etiology of maternal mortality in developing countries: what do verbal autopsies tell us? Bull world Health Organ 2001; 79(9): 805-810.

12. Censos 90. 2.o Recenseamento Geral da Populacäo e Habitacäo. Praia: DireccäoGeral de Estatística, 1992. 
13. EIU. Country report. Congo (Brazzaville), São Tomé and Principe, Guinea-Bissau, Cape

Verde. London: Economist Intelligence Unit, 1997.

14. Wessel H, Reitmaier P, Dupret A, Rocha E, Cnattingius $S$ and Bergström S. Deaths among women of reproductive age in Cape Verde: causes and consequences. Acta Obstet Gynecol Scand 1999; 78(3):

225-232.

15. Carreira A. The People of the Cape Verde Islands: Exploitation and Emigration. Translated from the Portuguese and edited by Christopher Fyfe. London: C. Hurst, 1982.

16. UN. Country presentation: Cape Verde. Second United Nations Conference on the Least Developed Countries. United Nations, 1990.

17. Inquérito demográfico e da saúde reprodutiva 1998.Praia: O Instituto Nacional de Estatística, 1998.

18. Thaddeus S and Maine D. Too Far to Walk: Maternal Mortality in Context. New York:

Columbia University, 1990.

19. Essien E, Ifenne D, Sabitu K, Musa A, Alti-Mu'azu M, Adidu V, et al. Community loan funds and transport services for obstetric emergencies in northern Nigeria. Int J Gynecol Obstet 1997; 59: S237-244.

20. Hjortsberg CA and Mwkisa CN. Cost of access to health services in Zambia. Health Policy Plann 2002; 17(1): 71-77.

21. Karim MS. Disease pattern, health services utilization and cost of treatment in Pakistan. I Pak Med Assoc 1993; 43(8): 159-164.
22. Egunjobi L. Factors influencing choice of hospitals: A case of the northern part of Oyo State, Nigeria. Soc Sci Med 1983; 17: 585-589.

23. Nnadi EE and Kabat HF. Choosing health care services in Nigeria: A developing nation. J Trop Med Hyg 1984; 87: 47-51.

24. Kloos H. Utilization of selected hospitals, health centres and health stations in central, southern and western Ethiopia. Soc SciMed 1990;31(2): 101-114.

25. Odero W, Garner $\mathrm{P}$ and Zwi A. Road traffic injuries in developing countries: a comprehensive review of epidemiological studies. Trop Med Inter Health 1997; 2: 445-460.

26. Soderlund $\mathrm{N}$ and Zwi AB. Traffic-related mortality in industrialized and less developed countries. Bull World Health Organ 1995; 73: 175-182.

27. Graitcer P. Injury. In: Howson CP, Harrison PF, Hotra D and Law M (Eds.). In Her Lifetime: Female Morbidity and Mortality in sub-Saharan Africa. Washington DC: National Academy Press, 1996 , 169-182.

28. Winston CM and Patel V. Use of traditional and orthodox health services in urban Zimbabwe. Int J Epidemiol 1995; 24(5): 100-612.

29. Hielscher S and Sommerfeld J. Concepts of illness and the utilization of healthcare services in a rural Malian village. Soc SciMed 1985; 21(4): 469-481. 